\title{
Life Cycle of Laboratory-Reared Acrobasis nuxvorella Neunzig (Lepidoptera: Pyralidae): A Pecan Nut Pest
}

\author{
${ }^{1}$ Corella-Madueno Alba Guadalupe, ${ }^{2}$ Fu-Castillo Agustin, \\ ${ }^{3}$ Harris Marvin, ${ }^{1}$ Martinez-Tellez Miguel Angel and ${ }^{1}$ Vargas-Arispuro Irasema \\ ${ }^{1}$ Centro de Investigacion en Alimentacion y Desarrollo, \\ A.C. Km 0.6, Carretera a la Victoria, Hermosillo, Sonora, CP 83000, Mexico \\ ${ }^{2}$ Instituto Nacional de Investigaciones Forestales, \\ Agricolas y Pecuarias-Costa de Hermosillo, Km, 12.6 Carretera a Bahia Kino, Hermosillo, Sonora, Mexico \\ ${ }^{3}$ Department of Entomology, Texas A\&M University, College Station, TX 77843-2475, TX, USA
}

Received 2012-07-12, Revised 2012-08-31; Accepted 2012-09-06

\begin{abstract}
Acrobasis nuxvorella Neunzig is a monophagous pest that feeds on pecan nut trees, Carya illinoinensis. Its specific feeding habit makes the reproduction of this insect in the laboratory challenging. The objective of the present work was to replicate the biological cycle of $A$. nuxvorella under laboratory conditions. Different instar larvae of the insect were collected from infested nut trees. The larvae were fed with a simple diet consisting of immature frozen nuts $\left(-20^{\circ} \mathrm{C}\right)$ that were ground before use. We managed to complete the whole life cycle and to record the dates of the appearance of pupae, the emergence of adults, egg laying and egg hatching. These eggs gave origin to the second larvae generation. The laboratory conditions to maintain the moths consisted of a photoperiod of $16: 8 \mathrm{~h}$ at $25 \pm 2^{\circ} \mathrm{C}$ and $60 \pm 5 \%$ of RH. The total duration of the cycle was 45 days, which is similar to the duration of the natural cycle in the field. The emergence of adults was $83 \%$. The time of larval development was longer than the time spent as pupae and this latter was longer than the time spent as eggs. Hatching occurred four days after oviposition (time 0 ) and ecdyses of the remaining four larval instars lasted an average of 22 days in total. The pupal stage, during which they did not feed, lasted between 10 to 14 days and the adult life lasted 8 to 10 days. These results allow the standardization of the conditions needed to rear $A$. nuxvorella in the laboratory, which was not possible until now. Furthermore, this breakthrough will improve techniques to control and manage this insect.
\end{abstract}

Keywords: Carya Illinoinensis, Lepidoptera Diet, Pecan Nut Casebearer

\section{INTRODUCTION}

The Pecan Nut Case bearer (PNC), Acrobasis nuxvorella Neunzig (Lepidoptera: Pyramidal), is the most damaging pest of pecan, Carya illinoinensis (Wang) K. Koch (Juglandaceae), in the southern USA and Mexico (Harris et al., 1998). In Mexico, PNC can be found in the states of Chihuahua, Coahuila, Nuevo Leon and Durango and recently expanded to pecan growing regions in Sonora, Mexico (Harris et al., 2008), where pecan nut crops represent one of the principal agricultural activities. PNC constitutes a primary pest not only because of the annual damage it causes in commercial orchards (fruit loss of up to $80 \%$ ), but also because of the difficulty in controlling the population. Damage to pecans is a result of PNC larvae burrowing into and feeding on pecan nutlets and therefore, insecticides can hardly reach it. The small larvae of PNC overwinter in a structure called hibernacula at the base of a dormant pecan bud. The larva becomes active at bud break and grows and develops by tunneling in buds and shoots. Following pupation and mating, the overwintering generation females begin laying first summer generation eggs, tigacion en Alimentacion y Desarrollo, A.C. Km 0.6,

Carretera a la Victoria, Hermosillo, Sonora, CP 83000, Mexico 
giving rise to the first pest generation. PNC is mutivoltine, having typically 3-4 generations per year, depending on climate and geographic location (Grantham et al., 2002). The first-generation larvae are more destructive to pecan crops due to the small size of the nutlets on which they are feeding. These firstgeneration larvae are capable of consuming 3-4 nutlets in a cluster (Ring and Harris, 1984). The larvae of subsequent generations require fewer nutlets to complete development and thus are less damaging to the crop. $\mathrm{PNC}$ is monophagous on pecan, which also hampers the implementation of insecticides (Millar et al., 1996). The limited effectiveness of authorized insecticides highlights the need to find new forms of control. However, studies aimed at finding control alternatives are limited by the short time in which the insect is present in a year ( $\sim 6$ month). Although during any given year, there may be up to four generations in which it is possible to study the insects, is needed development of controlled laboratory-reared techniques to PNC, which provide insects to continue with studies during the year which (Harris, 1983). An in-depth examination of the PNC life cycle may reveal additional insights to improve the effectiveness of pest management. The capacity of PNC to cause economic damage justifies intensive studies to uncover new information relevant for its control. Here, we proposed to replicate the cycle of PNC under laboratory conditions (controlled conditions of relative humidity, temperature and photoperiod) and thus obtain biological material for future studies that can be applied in the development of new control strategies.

\section{MATERIALS AND METHODS}

\subsection{Plant Material}

Immature nutlets $(8-10 \mathrm{~mm})$ of Western Schley and Wichita varieties with evident damage caused by the PNC were collected in pecan orchards at La Costa of Hermosillo, Sonora, Mexico. They were carried in paper bags to the Laboratory of Chemical Ecology of Centro de Investigacion en Alimentacion y Desarrollo, A.C. (CIAD, A.C.).

\subsection{Larvae Extraction}

The larvae were carefully extracted from the nutlets with a scalpel. They were placed in Petri dishes in groups of 6 to 10 .

\subsection{Formulation of the Food}

The larvae's diet consisted of $10 \mathrm{~g}$ of fresh immature nuts ground in a blender and kept in plastic bag at $4{ }^{\circ} \mathrm{C}$.
Small amounts of food were offered daily to the larvae until pupation began.

\subsection{Pupation}

L3 and L4 instar larvae pupated shortly after they were extracted from the nut. The remaining larvae continued to feed until they reached these stages of development and pupate. The dishes containing larvae in pre-pupae state were maintained in a growth chamber under controlled conditions: temperature $25 \pm 2^{\circ} \mathrm{C}$, relative humidity was held $60 \pm 5 \%$ and $16 / 8$ photoperiod (Reinecke et al., 1980; Moreira and Maldonado, 1985; Aguirre et al., 1995; Soto et al., 2001; Perez-Guerrero et al., 2004; Perez et al., 2005). The Petri dishes were examined daily under a stereo microscope and the size and external change in the morphology of pupae was recorded. This period lasted until adult emergence.

\subsection{Sex Proportion}

All pupae were measured using a micrometer under stereoscope (Am Scope. Model MD600E) and their sex was determined by locating the specific genital characters of the last abdominal segments; females have the genital opening to the right of next to the second to last segment and males have it in the middle part of the last segment. We maintained the pupae in small individual vials (Marco et al., 1993; Perez-Guerrero et al., 2004: Harris et al., 2008).

\subsection{Emergence of Adult Moths}

Male $(ð)$ and female (ㅇ) pupae were individually placed in petri dishes separated by sex until the adults emerged. The sex of the moths was corroborated by genital inspection under a stereo microscope. To facilitate the observation of the external genitalia, adults were exposed to ethyl acetate vapors and their abdomens were softly pressed with flexible tweezers (Fernandez and Alvarez, 1988; Marco et al., 1993; Galicia et al., 2008). Furthermore, the size of male and female moths was measured and compared with the size of adult moths from wild populations reported in the literature (Harris, 1983).

\subsection{Mating Conditions}

Pairs of adults were placed in reproduction chambers, which consisted of transparent plastic boxes of $17 \mathrm{~cm}$ in length, $12 \mathrm{~cm}$ in height and $12 \mathrm{~cm}$ in width. These chambers had a rectangular opening of $8 \times 5 \mathrm{~cm}$ on the superior side through which 6 pairs of moths $(3$ males and 3 females) were introduced to the box; the opening had a plastic mesh to allow ventilation. Inside the boxes, there was a pecan shoot of $15 \mathrm{~cm}$ in a vial containing tap water to maintain the shoot as oviposition site. The boxes 
were maintained at $16 / 8$ photoperiod, with temperature of $25 \pm 2{ }^{\circ} \mathrm{C}$ and $60 \pm 5 \%$ of relative humidity for 5 to 10 days. A $10 \%$ sugar water solution was offered as food to the adults (Fernandez and Salas, 1985; Fernandez and Alvarez, 1988; Simmons and Lynch, 1990).

\subsection{Oviposition}

The observation of oviposition and egg quantification were carried out with a black background and a stereoscope (Am Scope. Model MD600E).

\section{RESULTS AND DISCUSSION}

\subsection{Larvae Development}

PNC larvae extracted from pecan immature nuts were classified as L1 instars. All larvae consumed a diet of ground immature nuts until they reached their normal development of L3 and L4 instars. In this process, we were able to observe the changes in color of different instars in the laboratory (Table 1). Recently emerged larvae were white in color, changing to reddish brown and, finally, jade green before they began to pupate. These color changes coincided with the four instars reported in the literature for PNC larvae feeding on pecan trees (Mulder and Grantham, 2001). The size of the larvae varied among instars; therefore, the classification of larvae was based on color. Although the precise identification of the larval instars requires basic entomological studies to define maturity of the larvae (Chapman, 1998), to this study we establish the classification of larvae based on color. Larvae reared under laboratory conditions reached $13-15 \mathrm{~mm}$ of length in the most mature instar (Table 1). It was possible to recognize the last molt of the larvae because the larvae exubiae were found next to the pupae.

\subsection{Pupation}

Larvae that reached the L3 and L4 instars were able to construct a cocoon of firm and cohesive structure on the Petri dishes (Fig. 1). The cocoon protects the larvae from the outside environment during the metamorphosis. The cocoons remained on the petri dishes until the pupa reached its total development, which was observed as a spontaneous liberation of the pupa from the cocoon (Fig. 2). The pupal stage lasted approximately 14 days (Table 2), similar to the duration of the biological cycle of PNC in a wild population (Harris, 1983). Cocoons that did not spontaneously liberate the pupae were removed from the dishes. Subsequently, we measured and identified the sex of the pupae. All the pupae were observed under a stereoscope to recognize the external characteristics (Fig. 3).

\subsection{Pupae Size and Sex Proportion}

There were no differences in pupae size between laboratory-reared pupae and pupae from wild populations. The pupa length was about 8 to $9 \mathrm{~mm}$, which is the usual length of PNC pupae in wild conditions (Harris, 1983; Mulder and Grantham, 2001).

The methodology used for the sex identification has been used for other Lepidoptera, even though the location of the genital opening varies in different species. The last segment of PNC pupae (Fig. 4) permits a relatively simple diagnosis (Marco et al., 1993; Santos et al., 2003; Perez-Guerrero et al., 2004).

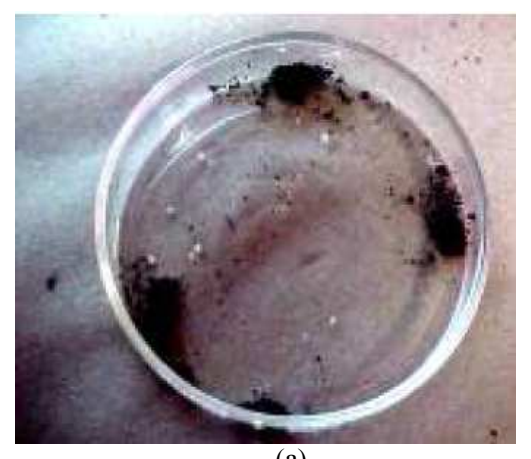

(a)

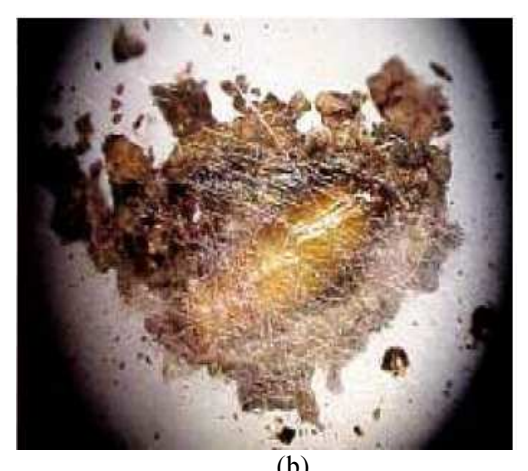

(b)

Fig. 1. Pupation stage of Acrobasis nuxvorella reared in laboratory conditions. (a) A. nuxvorella cocoons before pupation in petri dishes; (b) A. nuxvorella pupae inside a cocoon

Table 1. Larval size of Acrobasis nuxvorella reared in laboratory conditions

\begin{tabular}{ll}
\hline $\begin{array}{l}\text { Larval Instar } \\
\text { (color) }\end{array}$ & Size $(\mathrm{cm})$ \\
\hline Neonate (white) & $0.2-0.3$ \\
L1 (yellow) & $0.3-0.7$ \\
L2 (yellow-green) & $0.7-1$ \\
L3 (reddish brown) & $1-1.2$ \\
L4 (jade green) & $1-1.5$ \\
\hline
\end{tabular}




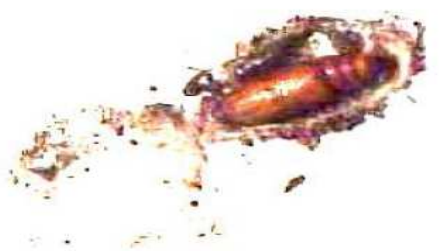

(a)

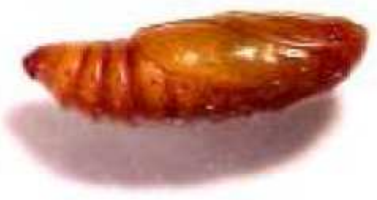

(b)

Fig. 2. Process of liberation of a pupa from

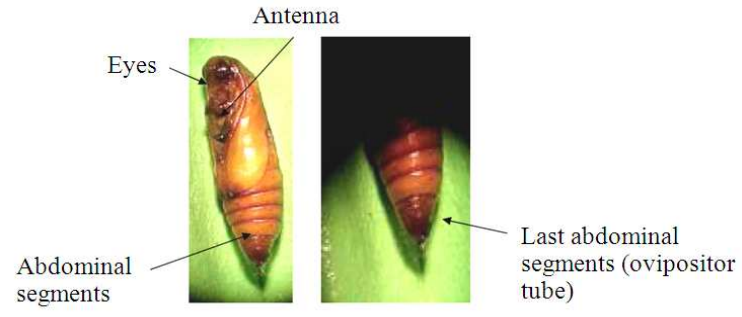

Fig. 3. External morphology characteristics of Acrobasis nuxvorella pupa stage

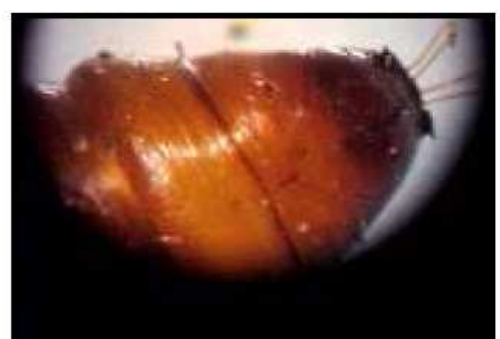

(a)

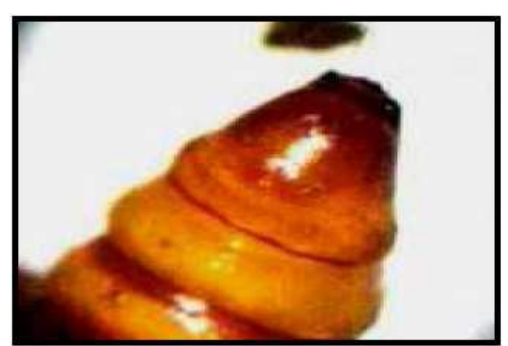

(b)

Fig. 4. Location of the genital opening in the last segment of the Acrobasis nuxvorella pupae, an important character for sex identification (a) Female (b) Male

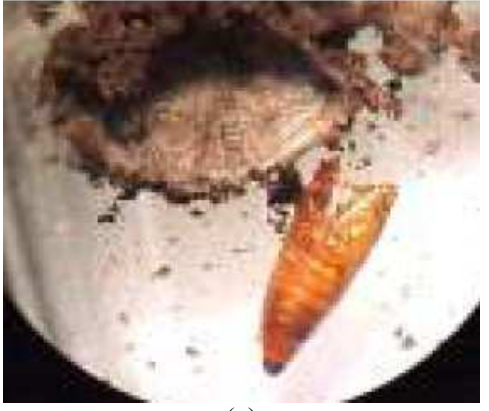

(a)

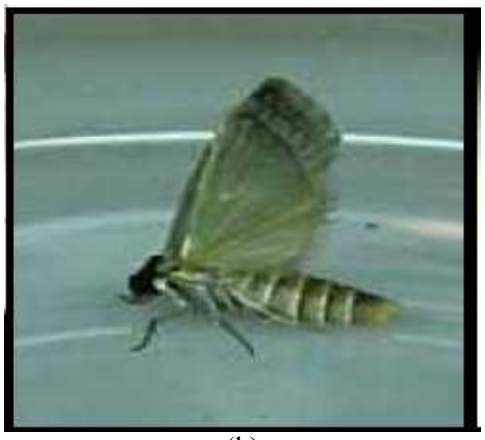

(b)

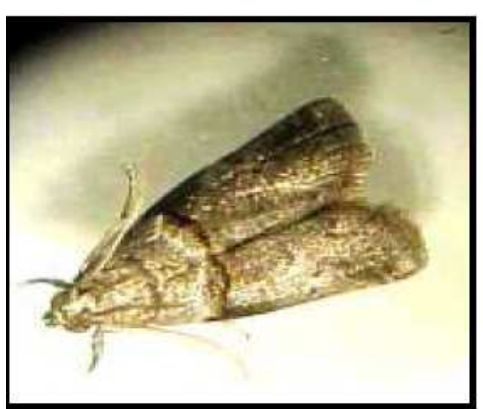

(c)

Fig. 5. Acrobasis nuxvorella adult emerged from its pupa case in the laboratory (a) Emerging moth leaving the pupa (b) Neonate moth (c) Adult moth

Table 2. Duration of the different stages of Acrobasis nuxvorella reared in laboratory conditions

\begin{tabular}{lccc}
\hline \multicolumn{4}{c}{ Time (days) } \\
Instar & Minimum & Maximum & Average \\
\hline Egg & 2 & 5 & 3.5 \\
Larvae & 20 & 25 & 22.5 \\
Male pupae & 10 & 20 & 14.5 \\
Female pupae & 13 & 15 & 14.0 \\
Adult longevity (days) & & & \\
Male & 10 & 13 & 11.5 \\
Female & 10 & 15 & 12.5 \\
Pre-oviposition & 2 & 4 & 2.0 \\
Oviposition & 6 & 10 & 8.0 \\
\hline
\end{tabular}


Based on our identification, there were a larger number of males than females. In addition, female moths were bigger than males, as in wild populations. These results are consistent with those published for other Lepidoptera species (Marco et al., 1993).

\subsection{Adult Emergence}

After 14 days of pupation, the adults emerged (Fig. 5). Moths were gray to dark gray in color, 7 to $9 \mathrm{~mm}$ in length with a dark ridge of scales on the forewings. The first emergence of adults represented $83 \%$ of the total pupae. A second emergence occurred 20 days after pupation (PNC) and represented a $1 \%$ of the total pupae. After this time there were no more emergences and $16 \%$ of the pupae did not emerge at all. The second emergence is not reported in the literature, but it occurred every time that we repeated the cycle ( 5 times); therefore, we believe that it is due to the laboratory conditions. The sex of emerged adults was confirmed by observing the terminal edge of the abdomen. In females, the ovipositor system, which is a delicate tube, is exposed. In males, the harpagones, which are similar to the head of a tong (Fig. 6), are observed (Marco et al., 1993). After this observation, we could confirm that the pupae sex determination was correct.

\subsection{Oviposition}

Females oviposited $50 \pm 10$ eggs over pecan shoots. The eggs were of foamy aspect, oval form and small in size (about $0.3 \times 0.6 \mathrm{~mm}$ ). As the embryo developed, they changed color from white to pink (Mulder and Grantham, 2001). They hatched 4 to 5 days after the oviposition. Females oviposited fewer eggs than reported in the literature, which is 50 to 150 per female (Harris, 1983). The challenger for future projects is to increase the oviposition rate of females in laboratory conditions. The hatching time under laboratory conditions coincided with the time reported for field conditions (Harris, 1983).

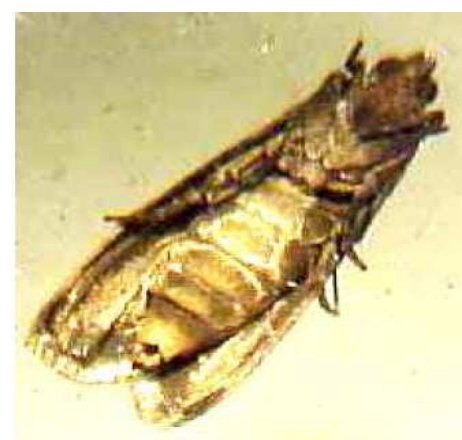

(a)

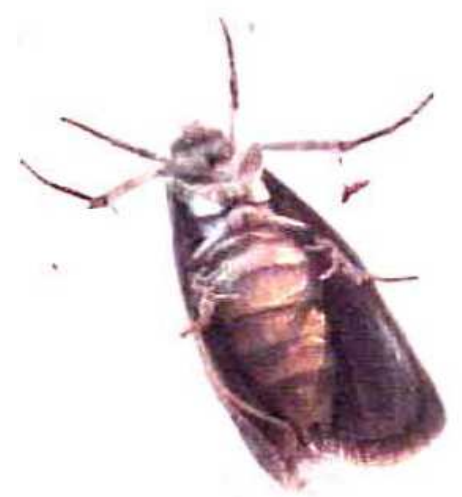

(b)

Fig. 6. External morphology of the Acrobasis nuxvorella genitalia emerged from pupae under laboratory conditions (a) Female; (b) Male showing the harpagons in the last abdominal segment

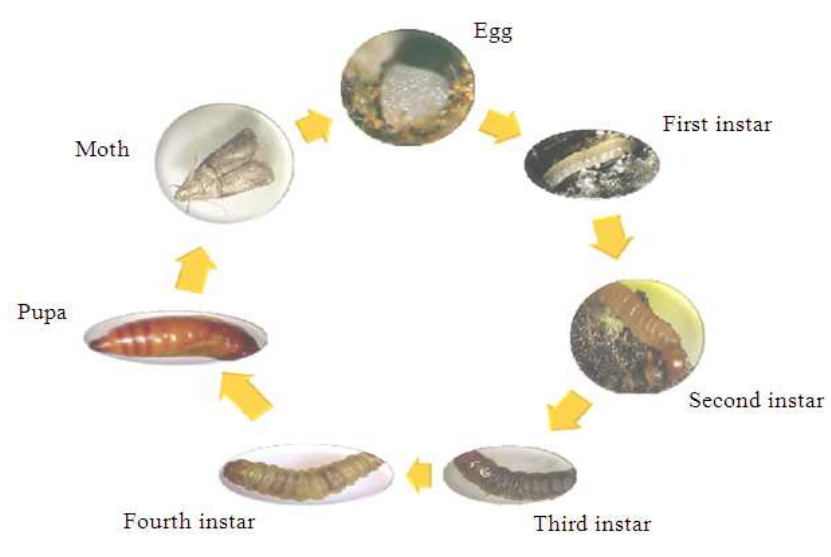

Fig. 7. Biological cycle of Acrobasis nuxvorella (PNC) reared in laboratory conditions 
Only $50 \%$ of the eggs hatched and the larvae emerged were healthy. These larvae were reared to form a new generation of PNC. In a future work are needed establishing suitable conditions for egg hatching, prevents dehydration and allows a high neonatal survival.

We were able to reproduce four times the life cycle of PNC in a laboratory conditions (Fig. 7). This holometabolous insect covers its nutritional requirements of the new shoots and pecan nuts, which provide the most beneficial conditions during all parts of the life cycle.

\section{CONCLUSION}

The biological cycle of $A$. nuxvorella in laboratory conditions lasted 45 days from the first instar larvae of the first generation collected in the field. These larvae completed all the stages of the cycle, such as cocoons, pupae, adult emergence, mating, oviposition and egg hatching in similar times to those reported for field conditions. One of the main challenges of this study was the maintenance of larvae and their development; however, it was possible to maintain larvae with the prepared diet and the whole biological cycle was completed for four generations. Further efforts are necessary to obtain a colony of PNC in the lab, which is essential to obtain biological material for further studies of this insect. This study constitutes the first report of an attempt to rear the PNC in laboratory conditions.

\section{REFERENCES}

Aguirre, A.L., M. Tucuch and M.K. Harris, 1995. Oviposition and nut entry behavior of the pecan nut casebearer Acrobasis nuxvorella Nuenzig. Southwest. Entomol. 20: 447-451.

Chapman, R.F., 1998. The insect: Structure and Function. 4 Edn., Cambridge University Press, Cambridge, ISBN-10: 0521570484, pp: 770.

Fernandez, S. and A.J. Salas, 1985. Estudios sobre la biologia del perforador del fruto del tomate neoleucinodes elegantalis guenee (lepidoptera: Pyraustidae). Agronomia Trop., 35: 77-82.

Fernandez, S.A. and C. Alvarez, 1988. Biologia de Plutella xylostella (L.) (lepidoptera: Yponomeutidae) polilla del repollo (Brassica oleraceae L.) En condiciones de laboratorio. Agronomia Trop., 38: 17-28.

Galicia, I., V. Sanchez and C. Cordero, 2008. On the Function of signa, a genital trait of female lepidoptera. Ann. Entomol. Soc. Am., 101: 786-793. DOI: 10.1603/0013-8746(2008)101[786:OTFOSA]2.0.CO;2

Grantham, R., P. Mulder, G. Cuperus and J. Carlson, 2002. Evaluation of pecan nut casebearer Acrobasis nuxvorella (Lepidoptera: Pyralidae) prediction models using pheromone trapping. Environ. Entomol., 31: 1062-1070.
Harris, M.K., 1983. Integrated Pest Management of Pecans. Ann. Rev. Entomol., 28: 291-318. DOI: 10.1146/annurev.en.28.010183.001451

Harris, M.K., A.A. Fu, H. Nunez, E. Aranda-Herrera and J.A. Moreira et al., 2008. A new pheromone race of Acrobasis nuxvorella (Lepidoptera: Pyralidae). J. Econ. Entomol., 101: 769-776.

Harris, M.K., B. Ree, J. Cooper, J.A. Jackman and J. Young et al., 1998. Economic impact of pecan integrated pest management implementation in texas. J. Econ. Entomol., 91: 1011-1020.

Marco, V., J. Jacas, F. Budia, A. Adan and P.D. Estal et al., 1993. Manejo de Ephestia kuehniella Zell. (Lepidoptera: Pyralidae) para evaluar la toxicidad de plaguicidas en laboratorio. Bol. San. Veg. Plagas, 19: 587-596.

Millar, J.G., A.E. Knutson, J.S. McEfresh, G. Gries and R. Gries et al., 1996. Sex attractant pheromone of the pecan nut casebearer (Lepidoptera: Pyralidae). Bioorg. Med. Chem., 4: 331- 339. PMID: 8733611

Moreira, M. and J. Maldonado, 1985. Biologia de Sitotroga cerealella olivier (Lepidoptera: Gelechidae) polilla de los cereales almacenados en venezuela. Agronomia Trop., 35: 117-124.

Mulder, P.G. and R. Grantham, 2001. The pecan nut casebearer. Oklahoma Cooperative Extension Service.

Perez, F.L.R., N.B. Martinez, J.V. Carrasco, O.M. Morales and S.Q. Luna, 2005. Comparación de dos tecnicas de medición de cápsulas cefálicas para separar estadios larvales de copitarsia incommoda (walker) (lepidoptera: noctuidae). Acta Zool. Mex. 21: 109-113.

Perez-Guerrero, S., A. El-Sayed Hatem and E. Vargas-Osuna, 2004. Metodo de cria de earias insulana boisduval (lep., noctuidae), plaga del algodon. Bol. San. Veg. Plagas, 30: 657-662.

Reinecke, J.P., J.S. Buckner and S.R. Grugel, 1980. Life cycle of laboratory-reared tobacco hornworms, Manduca sexta, a study of development and behavior, using time-lapse cinematography. Biol. Bull., 158: 129-140.

Ring, D.R. and M.K. Harris, 1984. Nut entry by 1 st summer generation pecan nut casebearer. Southwest. Entomol., 9: 13-21.

Santos, L.M., L.R. Redaelli, L.M.G. Diefenbach and C.F.S. Efrom, 2003. Larval and pupal stage of sSpodoptera frugiperda (J. E. Smith) (Lepidoptera: Noctuidae) in sweet and field corn genotypes. Braz. J. Biol. DOI: 10.1590/S1519-69842003000400009

Simmons, A.M. and R.E. Lynch, 1990. Egg production and adult longevity of spodoptera frugiperda, helivoverpa zea (lepidoptera: noctuidae) and elasmopalpus lignosellus (lepidoptera: pyralidae) on selected adult diets. Florida Entomol., 73: 665-671.

Soto, A., A. Norero, J. Apablaza and P.P. Estay, 2001. Requerimientos Termicos para el Desarrollo de Encarsia formosa (Hymenoptera: Aphelinidae) Criado en Trialeurodes vaporariorum (Hemiptera: Aleyrodidae). Cienc. Inv. Agric., 28: 103-106. 